\title{
A Study on Lean Manufacturing Practice Carried Out for Axle Housing Plant
}

\author{
Rishi J. P. ${ }^{1^{*}}$, Abhishek ${ }^{1}$, Srinivas T. R. ${ }^{2}$ and Ramachandra C. G. ${ }^{3}$ \\ ${ }^{1}$ Department of Mechanical Engineering, Vidya Vardhaka College of Engineering, Mysuru, India. \\ ${ }^{2}$ Department of Industrial and Production Engineering, Sri Jayachamarajendra College of \\ Engineering, Mysuru, India. \\ ${ }^{3}$ Department of Mechanical Engineering, Srinivasa Institute of Technology, Mangaluru, India.
}

\begin{abstract}
Lean Manufacturing is a way to deal with the elimination of waste through persistent change within the system. The assembling units in India should likewise hope to take its preferences. The Industries are energetically following the Lean assembling strategies to reduce waste and cost. The present work is the study of a manufacturing process for axle housing and to decide how Lean manufacturing process carried out for axle housing plant to improve productivity. The new shot peening machine was installed in a heat treatment plant of a housing line in an automobile rear axle assembly plant and material handling time from storage to this new machine was more and this increased lead time subsequently. To reduce this Kaizens technique was employed and a direct gravity conveyor was chosen and installed between two work stations and the part was directly fed to the new machine installed and this reduces the material handling time considerably. A cost analysis was done to realize the benefits of implementing this lean technique. Therefore reducing lead time and increasing productivity is the Prime benefits of lean manufacturing practices like lean assembly.
\end{abstract}

Keywords: Lean Assembly, Axle, conveyor, Kaizen.

\section{Introduction}

The axle housing contains different segments that take into consideration guiding, driving or load bearing. The real motivations behind the utilization of lean assembling are to expand efficiency, enhance product quality and reduce assembling process duration, diminish stock, lessen the lead time and dispense with assembling waste. To accomplish these, the lean assembling logic utilizes a few ideas, for example, one-piece stream, kaizen, cellular fabricating, synchronous assembling, stock administration, poka-burden, institutionalized work, work put association and scrap decrease to diminish producing waste[1]

\footnotetext{
*Corresponding author: rishijp@,vvce.ac.in
} 


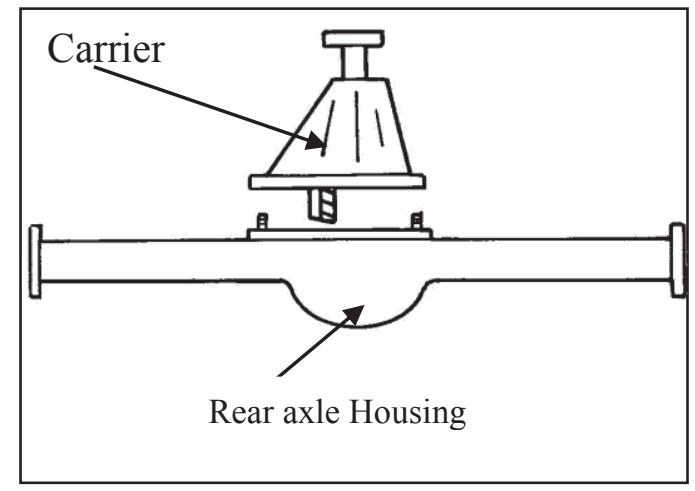

Fig. 1. Rear axle assembly

Sundareshan et al. [1] They carried out a literature review on Lean implementation in industries. The usually utilized lean apparatuses in the different association, most basic obstructions and advantages have been distinguished and recorded in this paper. Harsha Lingareddy et al. [2] They provided finding regarding implementations of $5 \mathrm{~S}$ techniques in any industry. This system helps in limiting the season of producing and furthermore builds the territory of work put. Vijayakumar et al. [3] Have carried out a case study on lean manufacturing techniques in garment industries. The fundamental topic of his paper has recognizable pieces of proof of huge issues identified with lean waste happens in $5 \mathrm{~s}$ of clothing have been measured utilizing particular lean devices and strategies. In this association, lean assembling idea is executed as another idea of assembling in the articles of clothing of the examined pieces of the clothing industry. Norani Nordin et al. [4] The reason for this paper is to investigate the degree of LM usage in Malaysian car producing firms. The outcomes demonstrate that a large portion of the respondent firms has actualized lean assembling framework up to a certain degree.

\section{Rear Axle Housing Assembly Process}

A detailed study of rear axle housing assembly layout was made to analyze various shortcomings of this layout. The 20 manufacturing processes carried out in housing plant are as follows.

Table 1. Overview of variety of Assembly process in a rear axle housing plant

\begin{tabular}{|c|c|c|}
\hline - $\quad$ Shot Blasting & - $\quad$ Friction Welding & - $\quad$ End Facing \\
\hline - $\quad$ Tack Welding & - $\quad$ Flange Tack Weld & - $\quad$ Key Way Milling \\
\hline - $\quad$ Seam Welding & - Cooling & - $\quad$ Flange Drilling \\
\hline $\begin{array}{ll} & \text { Repair welding and } \\
\text { surfacing }\end{array}$ & - $\quad$ Straightening & $\begin{array}{ll}- & \begin{array}{l}\text { Drain and breather hole } \\
\text { drilling }\end{array} \\
\end{array}$ \\
\hline - $\quad$ Straddle Facing & $\begin{array}{l}\text { Drain and breather hole } \\
\text { drilling }\end{array}$ & - Inside Painting \\
\hline $\begin{array}{ll}\text { - } & \text { Ring and Cover } \\
\text { Welding }\end{array}$ & $\begin{array}{ll}\text { - } & \text { Carrier and Cover } \\
\text { Boring }\end{array}$ & - $\quad$ Drying \\
\hline - $\quad$ Swaging & - $\quad$ Spindle Threading & -------- \\
\hline
\end{tabular}




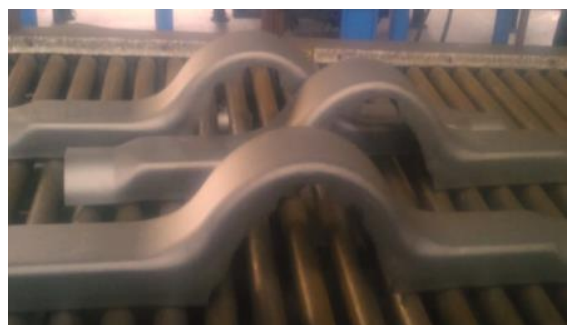

Fig. 2. Shot peening

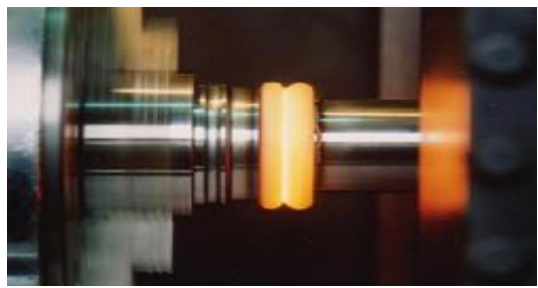

Fig. 4. Friction welding

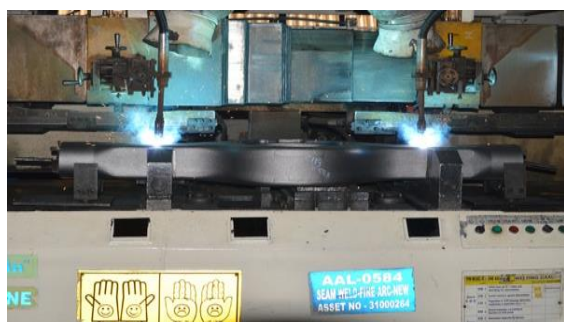

Fig. 3. Welding process

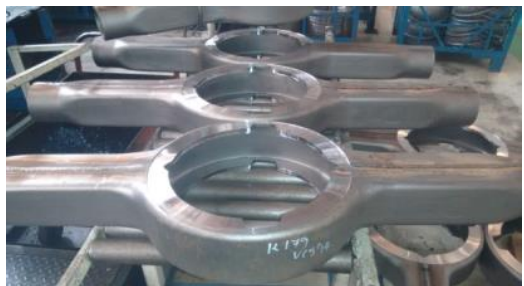

Fig. 5. Straddle facing

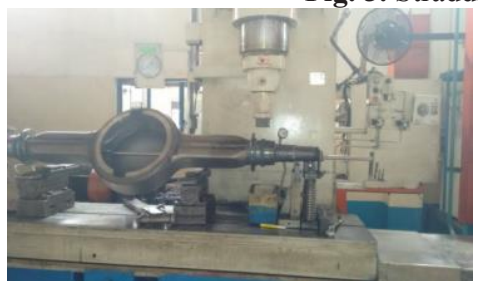

Fig. 6. Flange Drilling

Shot peening here is done to enhance surface finish of carriage assembly Fig. 2. Arc welding is done to join carrier to rear assembly Fig. 3. Friction welding is done to join the shafts Fig. 4.Straddle facing is done to remove any obligate present on the top plane of the surface Fig. 5. Drilling is done on the flange mounting purpose Fig. 6. This set of operations complete the entire assembly process.

\section{Analysis of Existing Process in Axle Housing}

\section{Material handling time is more}
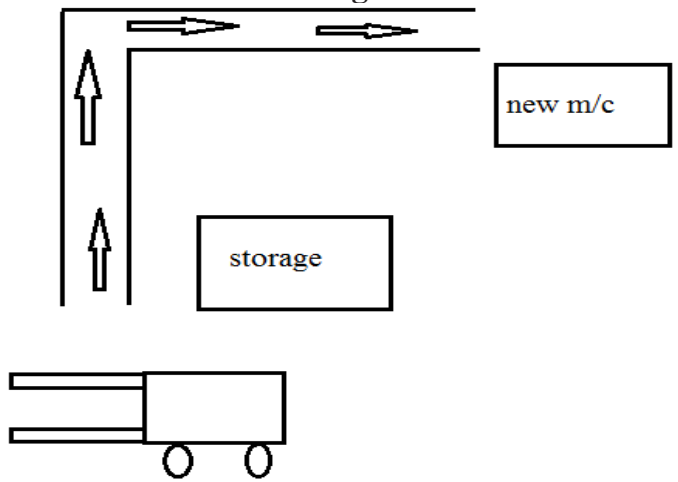

Fig. 7. Layout before (using forklift to lift material). 
A New shot peening machine was installed in a housing line of a Heat treatment plant in an Automobile Rear assembly plant at an offset distance. The material transfer for the shot peening machine is done through the forklift and required two workers one to load the material one to operate the fork lift. This Process was time-consuming and labor intensive. Thereby increasing labor cost because two labors are required and due to bottlenecking Lead time of production

\section{Kaizen -Solution}

Kaizen's is one of the most important techniques used to manage continuous improvement through observation and small modification within the system. Kaizen technique can be used to reduce lead time. In this situation, to eliminate the fork lift and replace it by a simple gravity conveyor which is a conduit kept at an inclination between storage bin and the new machine kept inline so that parts are directly fed to the new machine without waiting for transportation thereby reducing the material handling time and subsequently Lead time. By choosing a simple gravity conveyor both the performances can be achieved.
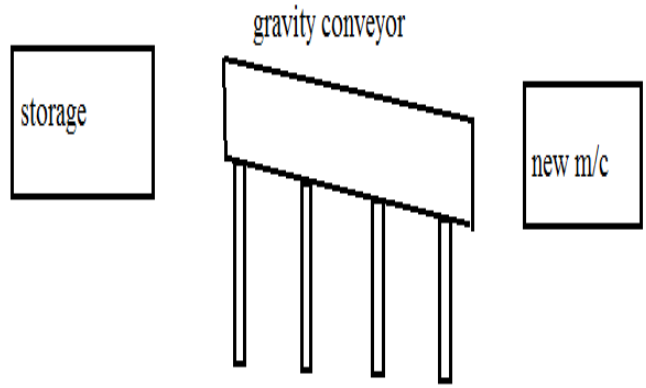

Fig. 8. Layout after (using conveyor)

\section{Methodology}

In order to realize this improvement following steps are considered while choosing a conveyor.

\subsection{Identifying the Problem}

The New heat treatment machine was installed in heat treatment section and the material supply for this new machine is done through Forklift. From storage to a new machine it has to cover a lot of certain distance. Hence the material handling time is more [7].

\subsection{Workspace Observation}

The Workspace between storage bin to the new machine is having a very small Distance. Hence this place can utilize to transport material to new heat treatment machine. (6-7 mts).

\subsection{Possible mechanism}

By using conveyor, the material can be transported from storage to new heat treatment machine. It is the suits the system for the given small area. 


\subsection{Given Task}

The given task is to make a conveyor without using any external sources.

\subsection{Work Volume}

The dimensions are measured and the area is calculated and volume is determined.

\subsection{Drawing}

After taking dimensions, mka detail plan is drawn using AutoCAD drafting software. The plan is a 2D drawing of simple gravity conveyor and its location.

\subsection{Implementation}

A simple gravity type conveyor is chosen and placed in between the storage bin and new machine as per the plan.

\subsection{Cost analysis}

A simple cost analysis to determine the benefits of implementing the lean technique.

\section{Results and Discussions}

The material handling time is more while supplying a material from storage to new machine with the help of the battery operated forklift. There are two workers involved in transferring material i.e. one is for the drive the forklift and another one in storage. By providing gravity conveyor from storage to new machine, manpower is eliminated and material handling time was reduced [8]. Before it took 5 minutes to complete the task.After implementation of Kaizen, the entire task was reduced to 1 minute. So by implementing Kaizen a total of 4 minutes can be saved to accomplish the task. Thereby optimizing labor and enhancing productivity and reducing lead time.

Table 2. Savings in time

\begin{tabular}{|c|c|c|c|c|}
\hline Items & Before & After & Difference & percent Improvement \\
\hline Set up time & $5 \mathrm{~min}$ & $1 \mathrm{~min}$ & $4 \mathrm{~min}$ & $80 \%$ \\
\hline
\end{tabular}

\subsection{Cost Analysis}

A simple cost analysis was carried out to understand the benefits of lean assembly as follows. Cost per minute of a line is calculated only for direct labors. Direct labors like operators, helpers, line supervisor and quality Inspectors. The two types of Cost per Minute of an assembly line are Estimated cost per minute of a line and Actual cost per minute of a line. 


\subsubsection{Estimated cost per minute of a Assembly line: ( $E$ ) - Existing cost}

This cost can be determined by considering total salary, Availablity and line efficiency.

$$
E=\frac{\text { Total salary of a line for one day }}{\text { (Total minutes available x Line efficiency in \%) }}
$$

To calculate total salary of a line includes all operators, helpers working in a line. We also include Quality Inspectors and line supervisors and feeder if they are not considered under overhead. So, we have to find following three parameters to calculate estimated cost per minute of a line [5]. Where,

Total minutes available $=$ Nos. of total labors $\mathrm{x}$ Daily working hours $* 60$

$$
\begin{aligned}
& =15 \times 08 \times 60 \\
& =7200 \mathrm{mins}(\text { for } 10 \text { machines })
\end{aligned}
$$

Total estimated salary of a typical line is INR 8000.00 and total manpower 15 of a 10 machines line and line efficiency is calculated as follows :

(A)Nos of operators $=15$; (B)Working hrs $=08$;

(C)Line output production $=25$; (D)Standard Allowable Min= 20;

(E) Total minutes produced by the line $=\mathrm{C} X \mathrm{D}=25 \mathrm{X} 20=500 \mathrm{mins}$

(F) Total minutes attended by all operators $=$ A X B X $60=15$ X08X60 $=7200$

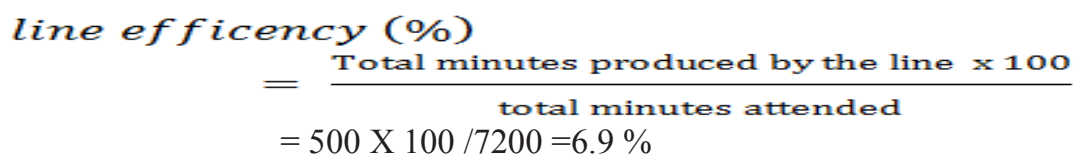

Cost per minute of the line $=(8000 /(15 \times 480 \times 0.69)=$ Rs 1.61

\subsubsection{Actual cost per minute of a line : (A) -Post Kaisen Implementation}

$=($ Actual salary for the day $/$ (Total garment produced $\times$ Standard Allowed Minutes $)$

Total actual salary of a typical line is INR 8000.00 , the line made 25 pieces and Standard

Allowed Minutes is 20 minutes through time study.

Therefore,

Cost per minute of the line $=(8000 /(400 \times 20))=$ Rs. 1

Table 3: Savings in cost

\begin{tabular}{|c|c|c|c|c|}
\hline Items & Before & After & Difference & percent Improvement \\
\hline cost per minute of a line & Rs 1.61 & Rs & Rs 0.61 & $37.8 \%$ \\
\hline
\end{tabular}

But from the implementation, point of view one battery operated forklift and its operating driver was eliminated which can be used in other section for further work [6]. 


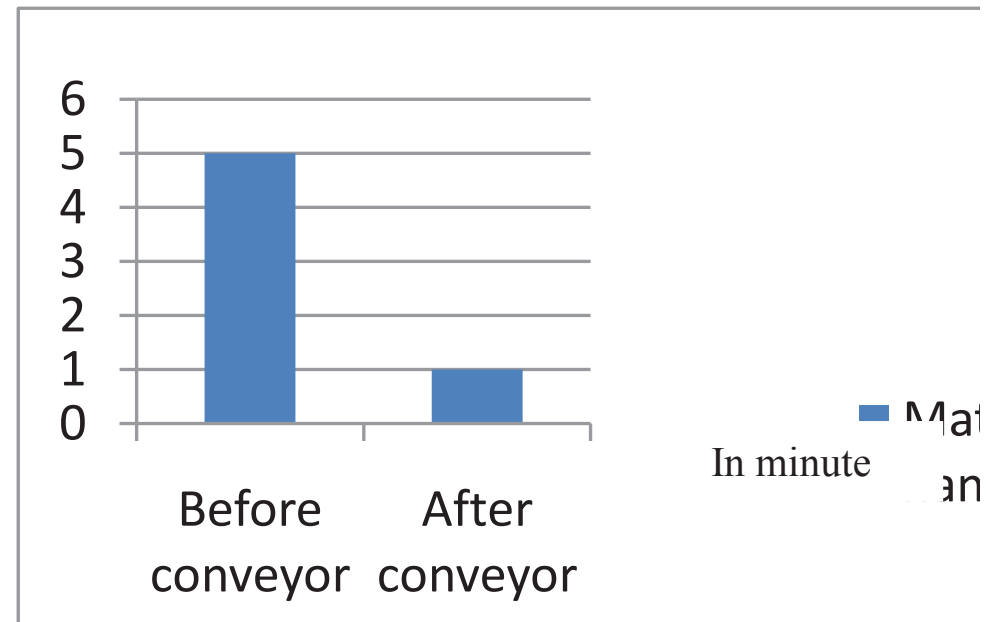

Fig. 9. Effect of using conveyor on assembly time

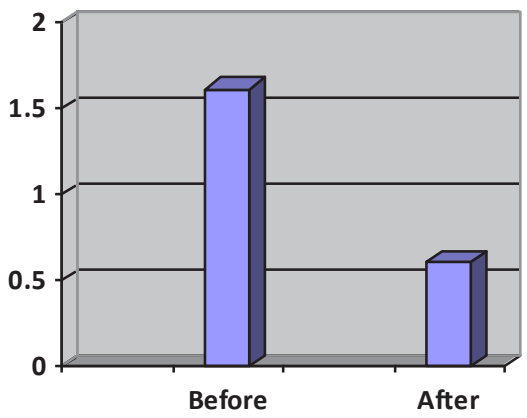

$\square$ Assy. Cost In RS

Fig. 10. Effect of using conveyor on assembly cost

\section{Conclusions}

This paper shows the major difficulties organizations confront in actualizing lean devices and procedures, maybe absence of far reaching and reasonable lean learning related to problems inside the organizations by the chiefs, absence of acknowledgment of lean culture in entire of the association and planning cause the failure inside the usage. Also, a few Manufacturers endeavor to upgrade the implementation by a portion of the lean devices and for the most part attempt to just execute the "ceaseless change" [9]._For the present study by making gravity conveyor from storage to new machine, manpower is eliminated and material handling time was reduced thereby the percentage savings in cost was $37 \%$ and saving in time was $80 \%$ both being substantial savings in resources. 


\section{References}

1. Sundareshan S D, “A Literature Review on Lean Implementations - A comprehensive summary", International Journal of Engineering Research and Applications, Vol. 5, Issue 11, (Part - 4) November 2015, pp.73-81.

2. Harsha Lingareddy, " $5 \mathrm{~S}$ as a tool and strategy for improvising the workplace", International Journal of Advanced Engineering Technology, Vol. IV/ Issue II/AprilJune, 2013/28-30.

3. G. Vijayakumar, "Impacts of lean tools and techniques for improving manufacturing performance in garment industry", International Journal of Advanced Engineering Technology, Vol. VII/Issue II/April-June, 2016/251-260.

4. Norani Nordin, "A survey on lean manufacturing implementation in Malysian automotive industry", International Journal of Innovation, Management and Technology, Vol. 1, No. 4, October 2010.

5. Bhasin, S. and Burcher, P. (2006). Lean viewed as a philosophy. Journal of Manufacturing Technology Management.

6. Dankbaar, B., 1997, "Lean production: denial, confirmation or extension of sociotechnical systems design?," Human Relations, 50(5).

7. Hayes, R.H. and Pisano, G.P., 1994. "Beyond world class: the new manufacturing strategy", Harvard Business Review, January-February.

8. Shah, R. and Ward, P.T., 2003. "Lean manufacturing: context, practice bundles, and performance",Journal of Operations Management.

9. Wilson, L. (2010) How To Implement Lean Manufacturing. New York: McGrawHillWomack, J., Jones, D.T. and Roos, D., 1990, "The machine that changed the world," Rawson Associates, NY. 